\title{
Application of well-seismic reservoir prediction technology in oilfield
}

\author{
Xiaona Zhang \\ Key Research Room, Institute of Geology, Fourth Oil Production Plant, Daqing Oilfield Co., Ltd., Daqing, Heilongjiang, 163511, China \\ zhangxiaona@petrochina.com.cn
}

\begin{abstract}
This study mainly takes the thick oil layer in Lamadian Oilfield as an example. This oil layer is mainly developed in the area dominated by fluvial sediments, and the reservoir sand body space changes frequently. If we only rely on the traditional single well logging data, it is difficult to directly and effectively predict the changes of the whole sedimentary sand body, and the spatial configuration relationship between river boundary and other sedimentary microfacies can not be effectively predicted. In order to effectively improve the understanding of cross-well sand bodies, it is necessary to effectively combine well seismic with reservoir prediction technology, give full play to the advantage of high resolution of well seismic in the longitudinal direction, and predict its specific adaptability and application according to different situations, so as to better improve the prediction accuracy of reservoir sand bodies and provide important information data for the rational adjustment of cross-well encryption and the formulation of effective measures to tap potential. Based on this, this article deeply analyzes the application value of well-seismic combined reservoir prediction technology in oil fields.
\end{abstract}

Keywords: Well earthquake, Oilfields, Reservoir prediction technology.

\section{Introduction}

In this study, taking the area of $17 \mathrm{~km} 2$ in the second area of Labeibei as an example, there are 1162 wells in total, and the distribution range of sand bodies is very wide in fluvial sedimentary environment. In the vertical direction, there are three development modes, namely, a large set of thick laminated sand bodies, a thin interbedded sand and mud model, and an isolated lenticular sand body with continuous distribution of river channels, interwoven strip distribution of river channels (branchlump sand bodies) and a single strip distribution mode of river channels. After four times of infill development, the overall distribution of both underground reservoirs and rivers in the study area is very complex. It is necessary to find new ideas and technical methods in continuous research and exploration, and only one step to strengthen the understanding and prediction of cross well sand bodies.

\section{Seismic reservoir prediction}

Seismic reservoir prediction can be roughly divided into two aspects, one is seismic correlation analysis, the other is attribute extraction. When extracting seismic attributes, different extraction methods need to be adopted according to the different meanings represented by each attribute in general. The correlation between seismic attributes and sand body can be directly analyzed by extracting its specific attributes, sand body distribution and sand body thickness. Simply speaking, it is the analysis of intersection diagram, and then the reservoir conditions are predicted by using the above-mentioned relationship. In this study, the pressure difference-flow method was mainly used to determine the starting pressure gradient of reservoir water flooding and emulsion flooding. The measurement can directly prove that the emulsion has significant application value in reducing seepage resistance and reducing the starting pressure gradient. At the same time, it can also provide important information and theoretical support for the displacement of oil reservoir emulsions. When the microemulsion flow passes through the small pores, the surfactants in the system can be directly adsorbed in the gaps, which can not only reduce the tension of the solidliquid interface, but also effectively reduce the seepage resistance in the boundary layer. In addition, ionic surfactants can effectively ionize the solution to generate charged particles. These so-called charged particles will directly enter the rear of the boundary layer, and will interact with ions in the boundary layer. Under the interaction, they will play the role of compressing and diffusing the electric double layer. At the same time, due to this effect, the boundary layer will gradually become thinner. Once the boundary layer is lower than the 
standard range, the actual overflow area in the pores will gradually increase. Based on this, microemulsion system can effectively reduce the gradient of starting pressure, and promote the seepage resistance to decrease gradually.

\section{Well-seismic reservoir description}

Taking the second area of Labeibei as an example, this paper mainly describes how well earthquakes combine with reservoirs, and the concentration of alkali and surfactant has certain influence on the interfacial tension of ternary composite system. In the whole experimental concentration range, the interfacial tension between the ternary composite system and crude oil will gradually decrease with the increasing concentration of alkali and surfactant [1]. When the concentration of alkali is greater than $0.2 \%$ and the concentration of surfactant is greater than $0.9 \%$, the tension between the ternary composite system and the crude oil will achieve ultra-low interfacial tension to a large extent. Taking the second area of Labeibei as an example, this paper mainly describes how well earthquakes combine with reservoirs, and the concentration of alkali and surfactant has certain influence on the interfacial tension of ternary composite system. If the concentration of surfactant is above 0 . $05 \%$, the interfacial tension can reach the order of $10 \sim 2$ $\mathrm{Mn} / \mathrm{m}$, but within the concentration range of the actual test, the interfacial tension does not reach ultra-low interfacial tension [2]. Therefore, by analyzing the construction of data centers in the international, domestic and petroleum fields, it is found that the construction of enterprise data centers can realize the development of integrated business, which can become the main way to enhance the competitive strength and position of enterprises in society, and at the same time provide important information and data for the production, management and decision-making of enterprises [3]. Therefore, by analyzing the application of information in domestic and foreign enterprises and institutions, it can be found that the construction of data center can better promote the process of enterprise informatization, realize the unified collection and storage of each core data, and realize the sharing of information resources.

\section{Verification of coincidence rate of well-seismic reservoir prediction technology}

In order to better explore the advantages of the combination of well earthquake and reservoir prediction technology applicable to the target layer in this study area,In this study, three methods were used to predict the inter-well reservoir conditions, This method mainly includes single amplitude attribute, multi-attribute neural network fusion, geostatistical inversion and prediction,At the same time, it is divided into two levels: sand layer group and sedimentary unit. Generally, each sand layer group includes four sedimentary units, and some sand layer groups contain three sedimentary units, The general thickness of single layer of deposition unit is about $4 \mathrm{~m}$ [4-5]. The single attribute prediction is mainly based on the well-point position and the correlation of the well seismic data to rationalize its specific attributes and slice conditions, so as to use it as the final choice, that is, the root mean square amplitude attribute. Use this attribute along the entire distribution trend of the layer slices to predict the distribution of the sandbody plane. At the same time, it is necessary to focus on the existence of the Saertugong oil layer group (hereinafter referred to as the sl oil layer group) and the SII oil layer group in this study. The seismic reflection axis of the top interface is strongly interfered with. At the same time, the wavelet decomposition and reconstruction technology is used to predict, which significantly improves the reflection effect of the overall target layer [6].

Geostatistical inversion usually adopts JAS (n) software to reconstruct the density curve with the participation of acoustic wave and resistivity, which can greatly improve the accuracy of wave impedance calculation, and then through the physical analysis of well seismic rock [7-8]. Determine the lithology sensitivity curve, seismic attributes and lithology division sensitivity values, and then use the natural potential pseudo-wave impedance inversion constraint to effectively combine the well seismic and geostatistics co-simulation technology process, which can be used to a large extent To ensure the accuracy of the response effect, improve the effectiveness of the inversion effect and the vertical high resolution [9].

By analyzing the application effects of these three different seismic prediction techniques in post-reservoir post-inspection wells (see Table 1),Compared with the single attribute technique, the multi-attribute technique has significantly improved the prediction coincidence rate of the later mudstone and $3 \mathrm{~m}$ thick sandstone, which can reach $90.01 \%$ and $88.58 \%$ respectively. By analyzing the data, we can directly clarify the specific distribution of this part of the reservoir. For the sedimentary unit level with an average stratum thickness of $4 \mathrm{~m}$, in the process of actual prediction, seismic inversion technology, that is, post stack geostatistical inversion, can significantly improve the prediction accuracy of thin sandstone with a thick bottom of less than $3 \mathrm{~m}$ and the prediction value of thin reservoir can be significantly improved compared with seismic attribute technology [10-21]. 
Table 1. Statistical table of coincidence rate of seismic prediction for different sandstone thicknesses

\begin{tabular}{|c|c|c|c|c|c|}
\hline \multirow{2}{*}{ Statistical unit } & \multirow{2}{*}{$\begin{array}{l}\text { Earthquake } \\
\text { prediction } \\
\text { technology }\end{array}$} & \multirow{2}{*}{$\begin{array}{c}\text { Seismic } \\
\text { prediction } \\
\text { coincidence } \\
\text { rate of } \\
\text { thickness } \\
\text { mudstone } \%\end{array}$} & \multicolumn{3}{|c|}{$\begin{array}{c}\text { Seismic prediction } \\
\text { coincidence rate of sandstone } \\
\text { with different thickness } / \% \text {. }\end{array}$} \\
\hline & & & $0-2 \mathrm{~m}$ & $2-3 m$ & $>3 \mathrm{~m}$ \\
\hline \multirow{2}{*}{$\begin{array}{c}\text { SII1-3 } \\
\text { (Sand group } \\
\text { level) }\end{array}$} & $\begin{array}{l}\text { Rms amplitude } \\
\text { attribute }\end{array}$ & 78.5 & 28.5 & 44. 4 & 75.3 \\
\hline & $\begin{array}{l}\text { Multi-attribute } \\
\text { neural network } \\
\text { fusion. }\end{array}$ & 90.9 & 33.2 & 49. 8 & 88.5 \\
\hline \multirow{3}{*}{$\begin{array}{l}\text { SII1+2b } \\
\text { (Sedimentary } \\
\text { unit level) }\end{array}$} & $\begin{array}{l}\text { Rms amplitude } \\
\text { attribute }\end{array}$ & 63.2 & 27.7 & 39.6 & 78.5 \\
\hline & $\begin{array}{l}\text { Multi-attribute } \\
\text { neural network } \\
\text { fusion. }\end{array}$ & 83.7 & 32.4 & 46.2 & 88.4 \\
\hline & $\begin{array}{c}\text { Post-stack } \\
\text { geostatistical } \\
\text { inversion } \\
\end{array}$ & 82.5 & 66.7 & 78. 2 & 88.7 \\
\hline
\end{tabular}

\section{Conclusions}

In conclusion, by effectively combining the selected seismic attributes with single well sedimentation, a complete sedimentary facies result map of the target horizon can be made. By analyzing the renderings, we can directly evaluate and analyze the connectivity between wells, and effectively identify the ineffective circulation layer with low efficiency. According to its analysis and evaluation results, the development of oil and water wells can be accurately subdivided and adjusted, and at the same time, the changes in the injection-production relationship between wells where the sedimentary facies diagram has changed can be accurately identified.

\section{References}

1. Wei Feng, Xue Guoqing, Xiong Cong, et al. Classification and comprehensive evaluation of facies-controlled reservoirs in sparse well areas combined with well-seismic: Taking the Zhujiang Formation of the WC-A Oilfield in the Pearl River Mouth Basin as an example[J]. Journal of Oil and Gas Technology, 2020, 42(2): 17-26.

2. Wei Feng, Xue Guoqing, Xiong Cong, et al. Classification and comprehensive evaluation of facies-controlled reservoirs in sparse well areas combined with well-seismic_-Taking Zhujiang Formation of WC-A Oilfield in Pearl River Mouth Basin as an example[J]. Journal of Oil and Gas Technology ,2020,42(02):17-26.

3. Ma Yuliang, Zheng Huan, Xie Ruijie, et al. Several main problems and processing methods of well seismic data in reservoir prediction $[\mathrm{J}]$. Science Technology and Engineering, 2019, 19(33): 132-138.

4. Li Suhua, $\mathrm{Hu} \mathrm{Hao}, \mathrm{Zhu}$ Lan, et al. Identification and prediction of bioclastic shoal karst reservoirs in the Maokou Formation in Yuanba area, northern Sichuan[J]. Geophysical Prospecting for Petroleum, 2021, 60(4): 584-594.

5. Li Jianxiong, Gu Yuemin, Dang Huqiang, et al. A method for combined well-seismic reservoir prediction in high-density well pattern development areas: Taking the JN2 block of the SL basin as an example[J]. Petroleum Geophysical Prospecting, 2011, 46(3):457-462.

6. Zhao Weiping. Application of combined wellseismic attribute analysis technology in deep-water turbidite reservoir prediction[J]. Journal of Engineering Geophysics, 2016, 13(2): 213-220.

7. Guo Jigang, Nie Zhikun, Mao Chuanlong, et al. Application of multi-attribute fusion method in twodimensional seismic coal seam prediction: Taking the two-dimensional work area of Dacheng Uplift as an example[J]. Computing Techniques for Geophysical and Geochemical Exploration, 2020, 42(6)): 732-742.

8. Yang Feng, Nie Hui, Chen Hongtao, et al. Carbonate prestack reservoir prediction based on broadband seismic data: Taking Block B in the eastern margin of the Caspian Basin as an example[J]. Geophysical Prospecting for Petroleum, 2019, 58(4) :555-562.

9. Zhu Jianbing, Wang Xingmou, Feng Deyong, et al. The method and application of fluvial reservoir prediction based on bidirectional cyclic neural network[J]. Geophysical Prospecting for Petroleum, 2020, 59(2): 250-257.

10. Ma Manhong. Research on the salvage technology of falling objects in oilfield wells[J]. Chemical Management, 2013(10): 114-114.

11. Fan Longwen. Discussion on the technology of salvaging complex falling objects underground[J]. Henan Science and Technology. 2013(5)

12. Wu Qi. Handbook for Downhole Operations Engineers Beijing: Petroleum Industry Press. 2002:215-253

13. Ren Fade. Discussion on the method of salvaging falling objects in oilfield downhole operations [J]. Petrochemical Technology. 2016, 23 (8): 260

14. He Wang, Xie Liyun, Wei Ziyu. Evaluation of engineering geological suitability of long-distance natural gas pipeline project crossing areaComment on "Oil and Gas Pipeline Integrity Evaluation Technology" [J]. Xinjiang Geology, 2019, 37(4): Post 4 .

15. Wang Qingguo, Guo Min. Research on the influencing factors of gas pipeline integrity based on ISM and AHP[J]. Gas and Heat, 2019, 39(4): Postinsertion 1- Post-insertion 4.

16. Ma Bin, Jiang Feng, Ma Xuqing. Integrity evaluation technology of defective pipelines[J]. Gas and Heat, 2019, 39(5): 32-39.

17. Cui Ruixue, Wang Lin, Zhao Deyin, et al. Research on technology development of pipeline integrity management platform[J]. Contemporary Research in Chemical Industry, 2020(11): 108-110.

18. Jin Jian, Zhu Xueshan, Liu Yanyang, et al. Research on big data integration technology methods for oil and gas long-distance pipelines[J]. Oil and Gas Field Surface Engineering, 2020, 39(2): 77-81. 
19. Jiang Zhongan, Zheng Dengfeng, Zeng Fabian, et al. Research on the safety management model of oil and gas pipelines based on hazard theory [J]. Journal of Hunan University (Natural Science Edition), 2021, 48(4): 56-65.

20. Jia Shuai. The application of intelligent information technology in the integrity construction of the Beijing-Tianjin Second Oil Pipeline[J]. Oil and Gas Field Surface Engineering, 2021, 40(2): 97-102.

21. Hou Lina, Li Yuanpeng, Yan Wei, et al. Construction and fusion method of oil and gas field pipeline and station integrity management system[J]. Oil and Gas Field Surface Engineering, 2021, 40(3): 63-69. 